\title{
Managerial experiences on Pediatric surgical tumors in Tribhuvan University Teaching Hospital
}

\author{
Rameshwar Prasad Pokharel ${ }^{1}$ \\ 'Department of Surgery, Institute of Medicine, Tribhuvan University Teaching Hospital (TUTH), Kathmandu, Nepal.
}

\section{ABSTRACT}

Introduction: Pediatric tumors are least prioritized but serious problems. Multidisciplinary management improves survival. Incidences, types and follow up results on Nepalese pediatric tumors have not yet been studied. To highlight our center's experiences on pediatric tumors management and follow up is aimed.

Methods: All pediatric surgical tumors admitted in pediatric surgery unit from 2065-2070 BS werer studied. Patients evaluated with or without chemo / radiotherapy pre or post surgery. Total of 22 cases from age four months to 13 years were studied.

Results: Tumor detection shown highest in age group below 3 years, followed by 5-10 years. Mean age was 54 months. Most common problem (22.7\%) was Saccrococcygeal teratoma (histologically matured). Total $13 \%$ Nephroblastoma, $9 \%$ ovarian tumor, $9 \%$ Neuroblastoma and various others each were $4.45 \%$. Majority underwent surgical excision of tumors. Three cases pre surgery and 5 post-surgery, received chemotherapy. Rest had only excision of tumor mass. Follow up were from three weeks to five years period. During this period, two patients expired (one due to complication of second cycle of chemotherapy and second one died with severe aspiration after second laparotomy for intestinal obstruction one year after initial Nephroblastoma excision). One patient lost for follow up after excision of stage $\mathrm{V}$ Nephroblastoma and first cycle of chemotherapy.

Conclusions: Management of pediatric tumors is complicated. Thus it needs better multidisciplinary centre of excellence for satisfactory results. Management is directed according to incidence, types, standard management protocol, which is not studied yet in Nepal. Research on pediatric tumors is virgin area. Large scale studies need to conduct in detail and a center of excellence is essential to provide better services.

Keywords: follow ups; management; Nepalese population; pediatric tumors; types.

\section{INTRODUCTION}

Pediatric tumors are considered very complex diseases with poor prognosis. Children are not little adults because tumor pathogenesis, histological characters, behavior and their responses to drugs in children are different. ${ }^{1-5}$ Pediatric tumors are said to be relatively lower in incidence, approximately $3 \%$ in less than 15

Correspondence: Dr. Rameshwar Prasad Pokharel, Departmen of Surgery, Institute of Medicine, Tribhuvan University Teaching Hospital (TUTH), Kathmandu, Nepal. Email: dr.rpokharel@gmail.com, Phone: +977-1-412505, +977-1- 412303 . 
years population. ${ }^{2}$ However least priority has given for complete management on these problems. Different studies have shown that incidence of pediatric tumors since 1975 AD till 2002 AD, have increased more than $50 \%$ worldwide in industrialized and less industrialized nations. ${ }^{3-5}$ Recent detail study on pediatric tumors patho-physiology and treatment practices have shown that most tumors are curable or manageable. Survival rate has improved tremendously than last 40 - 50 years from $20 \%$ to at present $94 \% .^{2,6}$ In Nepal the incidence of pediatric tumors are also increasing along with increased population growth ( $1.35 \%$ in 2012 census). ${ }^{7}$

Majority of pediatric deaths among more than one year of age group in USA and Europe is due to cancers. ${ }^{6}$ Cancer kills more than other diseases as Cystic fibrosis, Muscular dystrophy, AIDS, Asthma and Juvenile diabetes mellitus in children.6,14 Most common cancers are leukemia and brain tumors, there after comes other tumors. Multidisciplinary managerial techniques, coordinated team approach and more specific and cell targeted medicines with less side effects made pediatric cancer patients more survival as acute lymphoblastic leukemia from $4 \%$, (50 years ago) to 94 $\%$ recently. ${ }^{2-6}$ These achievement are due to improved chemotherapy, radiotherapy and experienced gained on management procedures. ${ }^{6,8}$ Even this achievement of dramatic survival in pediatric cancers, still some survive below $50 \%$ but early detection of pediatric cancer is increasing $\cdot^{9-12}$

Development of sophisticated, specific and relatively safe (even in intra uterine age) diagnostic tools has increased early detection of tumors from intra uterine life to adolescent ages. The increasing trend of incidence of pediatric tumors has also seen even in Nepal.

Data based national authentic reports on pediatric tumors and its incidence and managerial follow ups among Nepalese children are published very few in literatures. Study on pediatric tumors in Nepal has yet to conduct in detail and published authentically. This is high time to study on these problems in extensive scale and plan accordingly to develop a center of excellence with multi disciplinary team within the country for better care. Study on pediatric cancers in Nepalese population is virgin area of research and need to develop standardized practices.

With this background, this study is aimed to highlight and share the patterns, situations of pediatric tumors, types, surgical management and follow up experiences at an emerging centre of excellence and tertiary care center, TUTH, Kathmandu, Nepal.

\section{METHODS}

All pediatric tumor patients admitted and managed in pediatric surgical unit, at department of surgery, TUTH from 2065 to 2070 BS are enrolled in this study. Medical Oncological problems, brain tumors, orthopedic tumors are excluded from the study. These problems are managed by respected departments in our institute. Close support and coordination with pediatric oncologists for pre and post operative chemotherapy established and managed accordingly. Follow up maintained according to recent hospital records and telephone conversations with patients and their care takers.

Total 22 patients (male, 11 and female 11) studied. Follow up period was from 3 weeks to 5 years. In operable cases total excision of tumors was done, where as non operable cases they were managed conservatively with single or combined methods of chemotherapy, radiotherapy. After down staging surgery was planned in this case but all tumor tissues melted (confirmed by CT Scan) after radiotherapy. Pre or post-surgical chemotherapy/radiotherapy were decided according to size of tumors, involved organs and metastasis. If histo-pathologically total excision of tumor with intact capsules proved, then they were excluded for post-surgery chemo/radiotherapy. If tumor mass is residual or involved adjacent structures or metastasis then post-surgical chemo/radio therapy was initiated accordingly. If residual tumor exists then, second surgical procedure was also planned to remove tumor mass after receiving chemo or radiotherapy therapy alone or with combination. Symptom free survival period was analyzed and showed non of our cases required second surgery. Recurrences of tumors were evaluated with Ultrasonogram and if necessary CT scan or MRI. However, very few cases needed re$\mathrm{CT}$ and $\mathrm{MRI}$ in our series.

Study cases were statistically analyzed and presented here. Age groups, types of tumors, type of treatment provided, follow up periods and pathological diagnosis are mentioned. Follow up results from few weeks to five years period analyzed for symptom free status.

\section{RESULTS}

Total 22 patients enrolled in this study, both sexes were of with equal distribution of 11 each (Table 1). Tumors presenting ages ranged from four months to 13 years. 


\begin{tabular}{|lllll|}
\hline Table 1. Age and sex distribution of pediatric tumors. & & \\
\hline Age & 3 & Male & Female & No of tumors \\
$<1$ year & 4 & 3 & 6 & 0 \\
$1-3$ years & & 4 & 8 & \\
$4-5$ yrs & 2 & 0 & 0 & 22 \\
$5-10$ yrs & 2 & 3 & 5 & 3 \\
10 yrs + & & 1 & 11 & 22 \\
Total & 11 & 3 & \\
\hline
\end{tabular}

The mean ages in months are 54.0, Standard deviation 50.6 and Median is 36.0 months.

Table 2. The patterns of tumors and their management are shown in Types of Pediatric Tumors.

\begin{tabular}{llccl} 
S.No. & Types of tumors & $\mathbf{n}$ & (\%) & Treatment provided \\
1. & Saccrococcygeal teratoma & 5 & $(22.7)$ & Excision of tumor mass. \\
2. & Nephroblastoma & 3 & $(13.63)$ & Total excision \\
3. & Ovarian cysts & 2 & $(9.09)$ & Total excision \\
4. & Neuroblastoma & 2 & $(9.09)$ & Excision and chemotherapy \\
5. & Lymphoma & 2 & $(9.09)$ & Excision and chemotherapy \\
6. & Angiolipoma & 1 & $(4.54)$ & Debulking of tumor. \\
7. & Haemangioblastoma & 1 & $(4.54)$ & Sclerotherapy \\
8. & Gastro intestinal stromal tumor & 1 & $(4.54)$ & Resection and anastomosis \\
9. & Abdominal mass with & 1 & $(4.54)$ & Resection and anastomosis chyl-ascites \\
10. & Retroperitoneal teratoma & 1 & $(4.54)$ & Total mass excision. \\
11. & Yolk sac tumor & 1 & $(4.54)$ & Excision and chemotherapy* \\
12. & Abdominal Testicular teratoma & 1 & $(4.54)$ & Laparotomy and excision \\
13. & Retroperitoneal sarcoma & 1 & $(4.54)$ & Chemotherapy \\
\hline
\end{tabular}

Total excision of tumors was provided for more than $50 \%$ (12) cases and chemotherapy after excision of mass was provided to five cases. Only one case has provided chemotherapy alone. Among other four cases, resection anastomosis was done in two and de-bulking of tumors in two.

Three patients had chemotherapy pre surgery for down staging of large mass and infiltrating adjacent organs and five were given post operative chemotherapy after histologically proved malignancy.

The pattern of histological findings of our series are shown as in (Table no 3).

\begin{tabular}{|c|c|c|}
\hline SN. & Histopathology & n (\%) \\
\hline 1. & Mature teratoma & $5(22.7)$ \\
\hline 2. & Neuroblastoma & $2(9.0)$ \\
\hline 3. & Wilm's tumor & $3(13.6)$ \\
\hline 4. & Ovarian cysts & $2(9.0)$ \\
\hline 5. & Spindle cell tumor & $1(4.5)$ \\
\hline 6. & Non Hodgkin's lymphoma & $2(9.0)$ \\
\hline 7. & $\begin{array}{l}\text { Gastro intestinal Stromal } \\
\text { tumors }\end{array}$ & $2(9.0)$ \\
\hline 8. 0 & thers & \\
\hline Total & & \\
\hline
\end{tabular}


Follow up of our cases were done from three weeks to five years are presented in table no 4.

\begin{tabular}{|ll|}
\hline Table 4. Follow up of cases after management. \\
\hline Follow up in months & No. in months \\
Average follow ups & 30 \\
Median follow up & 30 \\
Standard deviation & 42 \\
Maximum days of follow up & 60 \\
Minimum days & 21 days. \\
\hline
\end{tabular}

Follow up of these cases were mentioned from three weeks to 5 years. Among these patients, two expired. First, a 10 years female with yolk sac tumor died due to complication of second cycle of chemotherapy. She died after two months of surgical excision. The second case died due to severe aspiration after laparotomy for intestinal obstruction. She died after one year of initial Nephrectomy. . One case refused chemotherapy (Angiolipoma) initially after surgical removal of tumor mass but a year later she initiated chemotherapy in other hospital. One patient had malignant Saccrococcygeal teratoma where tumor was infiltrated to lower spinal cord. All tumor mass was removed intra operatively and then chemotherapy was initiated. After receiving first cycle of chemotherapy by this child, he lost to follow up even in telephone contacts. Other cases are tumor Free State during follow up period.

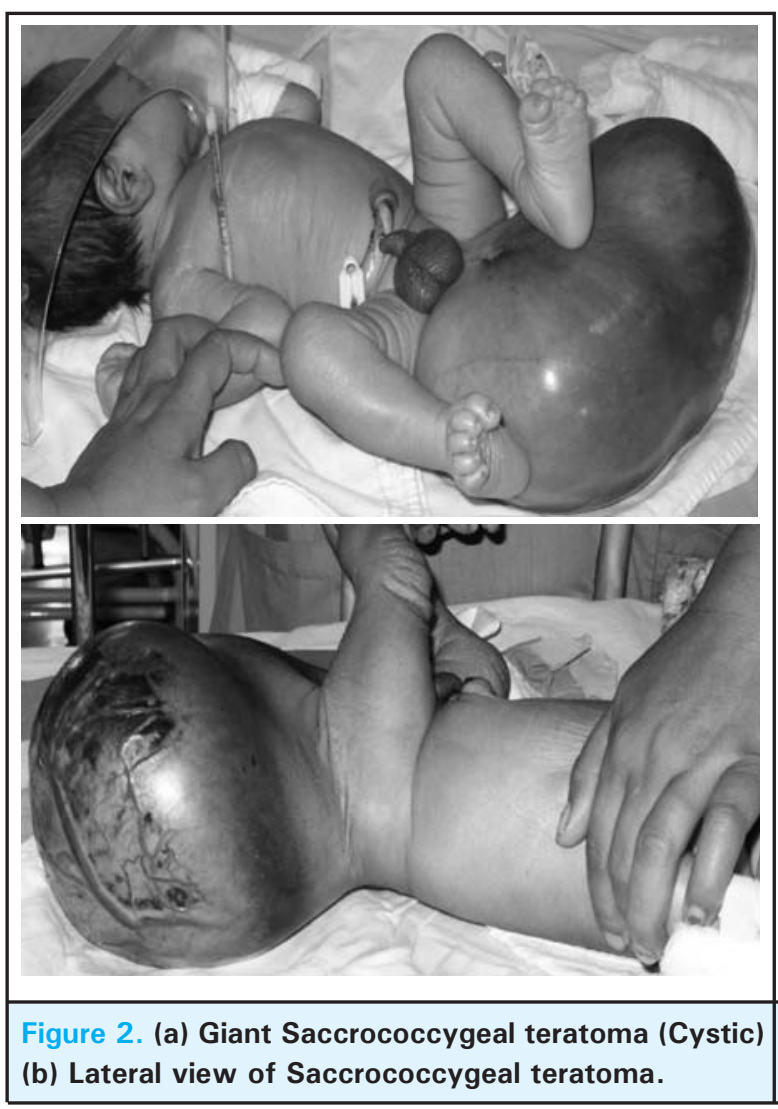

\section{DISCUSSION}

Pediatric tumors are said to be rare problems, however embryonic tumors are frequently encountered in daily practices. Most pediatric tumors are detected at the ages of less than three years which also proved in our study too. ${ }^{8,10-12}$ In our series out of 22 cases 14 cases were within three years age group. The second peak incidence of tumor detection has been shown at the age group 5-10 years. Average follow up period is 30 months and standard deviation is 41.8 months (ranges from three weeks to 5 years).

After total excision of tumors during surgical procedure without spillage of tumor cells up to stage two or three with chemotherapy is said to be tumor free. However in our cases, one patient developed recurrence of Neuroblastoma, in which inferior venecava, renal veins and renal arteries were all engulfed with tumor prior to surgery. Thus only de-bulking of tumor was done by removing the affected kidney. This patient had metastasis in lungs and is receiving chemotherapy and radiotherapy in combination and tumor is decreased in size and patient improved physically.

Ibrahim et al showed Saccro-coccygeal teratomas $(40 \%)$ as a most common among other tumors in their study. ${ }^{8}$ Where as in our series also highest incidence of pediatric tumors $(23 \%)$ has occupied by Saccrococcygeal teratoma. Ovarian tumors are more favorable histological findings as matured teratoma in children, where as in adult, malignant transformation of ovarian tumors are high. No recurrence of ovarian tumors after resection was present in our series. Testicular tumors are mentioned by Ibrahim's team is about $2 \%$. Where as in our series only one case was present in which orchiectomy. The case was performed and has not turned for follow up to us with any problems even after two years of surgery.

Well hydration, nutritional full support, close monitoring and multidisciplinary team approach in treatment has increased life span of pediatric tumor cases before and with or after chemotherapy. In younger children and adolescents social and psychological behavior counts a lot regarding their future life styles and fertility. Thus they need more attention and proper counseling which is a neglected issue in our part of world. ${ }^{13}$

In USA and Europe, most Wilm's tumor cases are cured and live normal adulthood life. However in some case with long term chemotherapy or their complications are major issues to the family and society. ${ }^{11-16}$

Our series has only limited numbers of pediatric tumor cases and are of different histological patterns. It shows variable standard and treatment practices. This needs 
to study more extensively for standardization. Majority of cases in our series are from remote village areas with multiple social and financial problems. They want to return their locations as early possible after surgery or after few cycles of chemotherapy / radiotherapy. Thus continuation of chemotherapy, radiotherapy or re do surgeries are very few. Priorities to treat cancerous children are probably secondary to these families. Thus nation wide a supportive system for cancer treatment in children is dire need. For these reasons we need national data on types, frequencies, geographical and ethnic distribution of pediatric tumors / cancers in Nepal.

\section{CONCLUSIONS}

Magnitude of pediatric tumors in Nepalese population has not yet authentically studied in detail. Most pediatric tumors are seen in less than three years group and second most common tumor age in pediatric is 5-10 years. Most pediatrician and pediatric surgeons and child care takers need to aware about detection of pediatric tumors early and referral for specific treatment on time. Frequently encountered problems are Saccrococcygeal teratoma. Total excision of tumor mass with or without chemo/radiotherapy increase survival of children and they almost live normal life. However severe side effects of chemo/radiotherapy may cause some degree of dependency, these needs to prevent with multidisciplinary team approach. Individual efforts on management of pediatric tumors have initiated, however it is not enough without extensive support. A multi-disciplinary team with well equipped center only can provide better services and improves survival of pediatric tumor cases. In Nepal it needs to study extensively and establish at least one center of excellence for better management of pediatric tumors.

\section{REFERENCES}

1. Tallen G, Dworzak M, Gadner H, Masera G, Main R, Eggert A, Schrappe M, Biondi A, Vassal G, Creutzig U. More and better cure for an orphan: Priorities for future pediatric cancer research in Europe - Meeting report of the EC-funded science-communication project DIRECT "Overcoming Cancer with Research". Memo. 2009;2:246-54.

2. Kupfer GM, Arceci J, Childhood Cancer Epidemiology[Internet] Medscape, 2013 Jul 11. Available from: http://emedicine.medscape.com/ article/989841-overview.

3. 3. Cancer in Children, Centre of disease control and prevention [Internet] USA, Medscape, 2009 (last reviewed,2009 July 30) Available from: http://www.cancer.org/cancer/ cancerinchildren/index?sitearea $=$ TARGET=_blank.

4. 4. Surveillance epidemiology and end results, National Cancer Institute, [Internet] USA. Medscape, 2009, July. Available from: http://seer.cancer.gov.

5. Childhood cancers: Basic facts and figures from Minnesota Department of health [Internet] USA, Medscape 2012. [Retrieved, 2012, Dec]. Available from: https://apps.health. state.mn.us/mndata/cancer_child.

6. Pui CH1, Campana D, Pei D, et al. Treating childhood acute lymphoblastic leukemia without cranial irradiation. N Engl J Med. 2009 Jun 25;360 (26):2730-41.

7. National Population and Housing Census 2011(National Report) Government of Nepal, National Planning Commission Secretariat, Central Bureau of Statistics ,Kathmandu, Nepal November, 2012.

8. Fakhr IM, Khalil el-SA, El-Baradie TS, Shaalan MA, Shalaby LM, Nassif SL, Farahat IG.The role of surgical management in pediatric germ cell tumors (GCTs), NCI case series. J Egypt Natl Canc Inst. 2008 Mar;20(1):70-9.
9. Coiffier B, Altman A, Pui $\mathrm{CH}$, Younes A, Cairo MS. Guidelines for the management of pediatric and adult tumor lysis syndrome: an evidence-based review. J Clin Oncol. 2008 Jun 1;26(16):2767-78.

10. Childhood cancer statistics at Cancer research [Internet] UK, 2012 [Updated: 2012, Nov 14.] Available from: http:// www.cancerresearchuk.org/cancer-info/cancerstats / childhoodcancer/follow-up.

11. Adkins S III, Coppes MJ. Pediatric Teratomas and Other Germ Cell Tumors. Medscape. 2009 July.

12. The incidence of paediatric tumor in Myo clinic report, [Internet], USA Medscape, 2012. Available from: http:// www.search.ask.com.

13. Reinmuth S, Liebeskind AK, Wickmann L, Bockelbrink A, Keil T, Henze G, Borgmann A. Having children after surviving cancer in childhood or adolescence - results of a Berlin survey.Klin Padiatr. 2008 May-Jun;220(3):159-65.

14. Fact about childhood cancer, Pediatric cancer genome project, [Internet] USA, St Jude Childrens' research hospital and Washington University in St. Louis, School of Medicine, Medscape 2013, 30 Jul 2013.Available from: http://www. pediatriccancergenomeproject.org.

15. Childhood cancer epidemiology[Internet], Medscape, 2013, [11 July 2013]. Available from: http://www.search.ask.com.

16. Kalapurakal JA1, Dome JS, Perlman EJ, Malogolowkin M, Haase GM, Grundy P, Coppes MJ. Management of Wilms' tumour: current practice and future goals. Lancet Oncol. $2004 \mathrm{Jan} ; 5(1): 37-46$. 